\title{
Chinese University Students' L2 Writing Feedback Orientation and Self-Regulated Learning Writing Strategies in Online Teaching During COVID-19
}

\author{
Jian $X \mathbf{u}^{1}$ (D)
}

Accepted: 26 April 2021/Published online: 7 May 2021

(C) De La Salle University 2021

\begin{abstract}
This mixed-method study explored Chinese university students' orientations towards written corrective feedback (WCF) and their use of self-regulated learning (SRL) writing strategies in online English writing courses during COVID-19. A questionnaire and semi-structured interviews were administered to 311 and 12 students, respectively. Results showed that during COVID-19, students generally held positive attitudes towards online WCF and teachers offered more tutorials and feedback that could be reviewed indefinitely, which created a comfortable learning space for students. Findings demonstrate that students used fewer social behaviour strategies than other strategies and the effectiveness of peer interaction was limited by peers' relatively low writing proficiency, tendency to give compliments, and the inconveniences of online communication. Students' feedback-seeking orientation was found to be positively associated with SRL writing strategies; the online interactions between teachers and students in relation to teachers' feedback motivated students to engage more in their subsequent writing practices. Pedagogical implications are discussed.
\end{abstract}

Keywords Feedback orientation .

Written corrective feedback .

Self-regulated learning writing strategies EFL writing . COVID-19 online teaching

\section{Jian Xu}

xujian@link.cuhk.edu.hk

1 School of Business English, Sichuan International Studies University, No.33, Zhuangzhi Road, Lieshimu, Shapingba District, Chongqing 400031, China

\section{Introduction}

Written corrective feedback (WCF), the "correction of grammatical errors for the purpose of improving a student's ability to write accurately" (Truscott, 1996, p. 329), has been a topic of theoretical and empirical interest in the field of second language writing for the past few decades, which has increasingly enabled us to understand how WCF works. Available studies have generally revealed the positive effects of WCF on second or foreign (L2) language learning (e.g. Nassaji, 2016). Despite the considerable studies conducted on WCF, the inconsistency of findings on the effectiveness of WCF on L2 writing still limits our understanding of this issue (Papi et al., 2019). One of the chief reasons for the inconsistencies relating to WCF has been the insufficient attention directed at learners' individual differences during the learning process (Ferris, 2010). As Ferris (2010) observed, "some students benefit more from corrective feedback than others" (p. 196). Individual differences in how L2 learners approach WCF showcase the influence of various factors, such as analytic ability (Sheen, 2007), age and working memory (Mackey \& Oliver, 2002), learner beliefs (Storch \& Wigglesworth, 2010) and so on. However, research concerning WCF typically centres on L2 learners' attributes and deems L2 learners passive recipients of different kinds of WCF instead of emphasising the agentive role that learners play in responding to WCF (Papi et al., 2019). To address this issue, Waller and Papi (2017) showed that L2 learners had two types of feedback orientation when receiving WCF: feedback-seeking orientation and feedback-avoiding orientation. Although emerging studies underscore the necessity and importance of exploring L2 learners' responses to WCF, the empirical evidence concerning L2 
learners' different feedback orientations towards WCF is scant in English as a foreign language (EFL) contexts.

WCF is important and valuable to Chinese university students. In the Chinese context, which is dominated by Confucian culture that features the authorities of teachers, students' learning behaviours are even more likely to be subject to teachers' instruction and feedback (Nguyen et al., 2006). As form-focused instruction prevails in Chinese English classrooms and students have few opportunities to use English outside classroom, WCF can help students to acquire particular grammatical structures and improve English writing proficiency (Chen et al., 2016). Chen et al. (2016) also reported that Chinese university students generally held a favourable attitude towards WCF, and they preferred to receive extended comments on both content and grammar of their compositions. However, Han (2019) argued that Chinese university students had various engagement with WCF, which is influenced by multiple learner and contextual factors. None of the reviewed studies, however, have explored Chinese undergraduate students' feedback orientation (seeking or avoiding) in EFL writing and how it impacts self-regulated learning (SRL) as it has been found that feedback orientation in L2 writing may have an effect on learning behaviours (Papi et al., 2019).

Beyond the understanding of students' feedback orientation, additional research is also needed to examine writing behaviours of students at the tertiary level, especially L2 self-regulation writing behaviours (Evans, 2013). Social cognitive theory posits that students' perceptions of themselves and others can influence their actions; cognition, environment, and behaviour are inter-correlated with each other (Bandura, 2011). According to this theory, teachers play a modelling role in classroom teaching and observational learning by way of modelling happens when students attend to a specific 'model' to code and retain information. Guided by the environmental forces (models), students will be motivated to learn and to be self-regulated. As such, teachers' feedback - the information provided by teachers to encourage students' better performance-exerts considerable influence on students' self-regulated learning (e.g. Havnes et al., 2012), which constitutes the theoretical underpinnings of this study.

Self-regulated learning (SRL) alludes to the extent to which learners are active participants in their own learning processes, and its importance lies in its impact on students' academic success and life-long learning and development (Zimmerman, 2000). Flower and Hayes (1981) divided writing into three iterative phrases during the writing process: pre-writing, during writing, and post-writing. Selfregulated writers are likely to employ multiple SRL writing strategies (Glaser \& Brunstein, 2007). SRL is a multidimensional construct in an L2 writing context that typically involves cognitive and metacognitive strategies, social behaviour strategies, and motivational regulation strategies (Teng \& Zhang, 2016). Empirical studies available have indicated that SRL writing strategies are associated with writing performance (e.g. De Silva \& Graham, 2015). Recent findings have reported that L2 writing self-efficacy and SRL writing strategies contribute significantly to students' writing proficiency (Sun \& Wang, 2020). Teng and Zhang (2016) proposed a new and comprehensive conceptualisation of SRL writing strategies which incorporates a new element of social behaviour strategies, so the present study adopted Teng and Zhang's (2016) classification of SRL in L2 writing. In the current study, cognitive strategies refer to students' abilities to process information and knowledge while completing a writing task; whereas, metacognitive strategies are the skills applied to regulate the cognition and control cognitive resources; social cognitive strategies indicate how contextual and environmental issues shape individuals' efforts to take control of their learning behaviours, and motivation regulation strategies involve how students use their beliefs and practices to sustain and enhance their engagement in a specific task. Few studies to date have investigated SRL in an EFL context to showcase how Chinese EFL learners utilise different SRL strategies in their L2 writing processes. In the Asian context where English is a foreign language, e.g. China, English writing is often demanding for EFL students and English writing has been the most challenging skill for EFL students to grasp (Wang et al. 2013). In addition, Chinese learners of English at tertiary level have a moderate level of L2 writing self-efficacy and infrequent use of SRL writing strategies (Sun \& Wang, 2020). The teaching of EFL writing in China is more test-driven and product-oriented, and teachers sometimes pay little attention to fostering students' writing interest and motivation; nor do they have time for helping students to be self-regulated writers who are able to use a variety of SRL writing strategies (Teng \& Zhang, 2016).

The literature has given significant attention to the impact of individual differences on the employment of SRL strategies in L2 learning, but insufficient attention to the application of SRL strategy in English writing (Bai \& Guo, 2018). The available research on L2 writing has been mainly devoted to the relationship between SRL writing strategies and writing performance (Palermo \& Thomson, 2018), motivation (Teng \& Zhang, 2016), and self-efficacy (Bai \& Guo, 2018). Empirical studies related to feedback orientation and self-regulated learning have shown that learners' perceptions of the writing feedback they obtain from course instructors in university settings mediates the effect of writing self-efficacy on writing self-regulation aptitude (Ekholm et al. 2015). This finding has been corroborated by a similar study of Zumbrunn et al. (2016) 
conducted in a different context. In addition, Waller and Papi (2017) found a positive relationship between learners' feedback-seeking orientation towards WCF and L2 writing motivation and a negative relationship between feedbackavoiding orientation and L2 writing motivation. However, none of the empirical studies reviewed above take a holistic view of exploring the relationship between feedback orientation towards WCF and SRL writing strategies by considering cognitive, metacognitive, social behaviours, and motivational regulation strategies. Besides, the examination of the effect of feedback orientation on feedbackseeking behaviours is insufficient in existing studies because they only concentrate on feedback-related beliefs and practices. In light of this situation, it is necessary to step further to probe into the association between feedback orientation towards WCF and SRL in L2 writing.

The outbreak and global spread of the Coronavirus (COVID-19) pandemic in early 2020 lead to major changes in the ways in which language courses are taught. L2 writing online instruction in this study refers to the replication of approaches used in face-to-face English writing courses and then the transformation to the online learning environment where instructors offer lessons via tools, such as zoom in a synchronous way, and teacher feedback is given in electronic written form in an online teaching forum; all the activities were completed online without face-to-face communications. This unprecedented transformation has brought about challenges for faculty because of insufficient online teaching experience and the lack of preparation and support from university technology teams, and it has additionally caused issues for students due to the difficulties in self-regulating their studies and sustaining their learning interests (Bao, 2020). Nevertheless, an online teaching environment affords benefits such as eliminated commutes and flexible working locations for teachers (Bailey \& Lee, 2020). Learners can also have more time to think and practice, study anywhere, and engage in various asynchronous and synchronous activities to improve language proficiency (Fageeh \& Mekheimer, 2013). At any rate, moving offline classes to a completely online environment is challenging for all, and this is doubtlessly the case for EFL writing courses, particularly when course instructors must offer the WCF online without live communications with students in person (Bailey \& Lee, 2020). In an online environment, previous studies have demonstrated that students who receive a combination of audiovisual and text-based achieve great improvement in their writing (Grigoryan, 2017). When looking into the effect of online WCF on the use of SRL writing strategies, Kheiri et al. (2019) showcased that there was no statistically difference between WCF in paper forms and WCF online, and the two forms of feedback made no differences in developing students' self-regulatory strategies.
Given that COVID-19 shapes teaching and learning in manifold ways, the present study was situated in the context of online EFL writing in Chinese universities to answer three research questions: (1) What was university students' feedback orientation towards written corrective feedback like in the online English writing course during COVID-19? (2) What were university students' self-regulated learning strategies like in the online writing course during COVID-19? (3) What are the relationships between students' feedback orientation and self-regulated learning strategies in the online writing course during COVID-19? By answering these questions, the present study can further our understanding of individual differences of learners in responding to WCF and their self-regulated learning behaviours and can add to the literature by examining how different feedback orientations may potentially impact students' cognitive, metacognitive, social behaviour, and motivation regulation strategies in this unique period, helping EFL writing teachers to provide more effective online feedback and facilitating students' SRL development in those teaching contexts that continue to be dealing with COVID-19 and in post-COVID-19 contexts.

\section{Methods}

To answer these research questions, the present study adopted a mixed-method concurrent explanatory design (Creswell, 2013), which encompasses a quantitative inquiry and semi-structured interviews. A questionnaire was administered to university students to investigate their orientation towards WFC and the use of SRL strategies, and a qualitative study consisting of one-on-one online interviews was conducted.

\section{Participants}

In total, questionnaires were collected from a valid sample of 311 Chinese university students aged from 18 to 21 , after removing the incomplete responses. Of the surveyed participants, there were 70 males $(22.5 \%)$ and 241 females (77.5\%); 58 first-year students (18.6\%), 154 second-year students $(49.5 \%), 67$ third-year students $(21.5 \%), 3$ fourthyear students (1.0\%), and 29 of unknown rank $(9.3 \%)$. The present study was conducted immediately after the surveyed participants had finished their online English writing courses. Twelve of the participants who agreed to participate in the follow-up interview were selected as interviewees. This interviewee group was made up of 1 male and 11 females, 6 first-year, 4 second-year, and 2 third-year students. 


\section{Instruments}

Two questionnaires and an interview protocol were, respectively, adapted and designed for data collection in the present study as follows.

\section{Feedback Orientation Questionnaire}

First, the feedback orientation questionnaire (FOQ) developed by Waller and Papi (2017) which aims to measure L2 learners' orientation towards WCF was used. This questionnaire focuses on two dimensions: feedbackseeking orientation (7 items) and feedback-avoiding orientation (6 items). Since this questionnaire was used in an online teaching environment during COVID-19 in this study, slight modifications were made. To be specific, we highlighted online teaching and learning for some questionnaire items and also emphasised COVID-19 on questionnaire instruction with the purpose of letting participants know that their responses should consider the COVID-19 online teaching environment. All the questionnaire items were on a 6-point Likert sale ( $1=$ 'Strongly Disagree'; $2=$ 'Disagree'; $3=$ 'Slightly Disagree'; $4=$ 'Partly Agree'; 5 = 'Agree'; 6 = 'Strongly Agree').

\section{Self-Regulated Learning Questionnaire}

The present study then employed a writing strategies selfregulated learning questionnaire (WSSRLQ) which was developed by Teng and Zhang (2016) specifically for Chinese learners of English in L2 writing context. This questionnaire comprises four dimensions: cognitive strategies (9 items), metacognitive strategies (9 items), social behaviour strategies (7 items), and motivational regulated strategies (15 items). Each dimension also includes sub-dimensions. Specifically, cognitive strategies include text processing and course memory; metacognitive strategies involve goal-oriented monitoring and evaluating, and idea planning; social behaviour strategies cover peer learning and feedback handling; motivational regulation consists of interest enhancement, motivational self-talk, and emotional control. Similar to the modifications made to the FOQ, we underlined online teaching during COVID-19 in the questionnaire instructions, and participants responded to the WSSRLQ on a 6-point Likert scale similar as feedback orientation scale.

As the original versions of the FOQ and WSSRLQ were both designed and formulated in English, we translated the English items into Chinese and then translated back into English to identify language inaccuracies before administering them. All of the translated Chinese items were checked to ensure their content validity. Then, the two questionnaires were sent first to an expert on English language education and then to a university student who had filled in the questionnaires, to obtain suggestions for further improvement. We revised the questionnaire items accordingly before distributing them to participants in the small-scale pilot study, which was then implemented with 72 university students. High reliability on these two questionnaires were achieved: feedback seeking orientation (Cronbach's $\alpha=0.76$ ), feedback avoiding orientation (Cronbach's $\alpha=0.72$ ), cognitive strategies (Cronbach's $\alpha=0.84$ ), metacognitive strategies (Cronbach's $\alpha=0.90$ ), social behaviour strategies (Cronbach's $\alpha=0.86$ ) and motivational regulation strategies (Cronbach's $\alpha=0.88$ ).

\section{Interview Protocol}

The interview protocol was designed to obtain the voices of students on what they thought about the online English writing course, online teacher WCF, and their own SRL writing strategy use during COVID-19. The design of interview protocol was based on previous empirical studies (e.g. Teng \& Zhang, 2016; Waller \& Papi, 2017). The interview protocol was closely related to the questionnaire survey in the ways that the interview protocols aimed to elicit how students perceived their own feedback orientation, and how they used SRL writing strategies. This interview protocol contained 18 questions (see Appendix). During the interview, these questions were adjusted organically to explore the reasons, motivations, and implicit feelings underlying the feedback orientation towards WCF and SRL writing strategies.

\section{Data Collection}

The questionnaire was distributed to participants via an online survey tool. A purposive sampling approach, which was considered a time-saving and cost-effective approach to identify the potential participants and obtain information-rich data (Patton, 2002), was adopted to select participants from five universities where English writing courses were being taught online. We first defined the surveyed population as Chinese learners of English in Chinese higher education context who have taken the online English writing courses. The five chosen universities were all top universities in China, and they were located in Beijing, Shanghai, Chongqing, and Shandong Province, roughly representing different regions in China. The selected universities all offered an online English writing course during COVID-19 in which teachers all used synchronous approach to teach online and offer WCF in electronic written form via the software of Zoom or VooV meeting. Prior to data collection, teachers' descriptions of their online English writing teaching were obtained to ensure that the selected universities all had similar teaching 
methods and provided electronic WCF with students. In each university, we tried our best to collect the responses as many as possible. All participants volunteered to complete the online questionnaire and were informed that the data would be used for research purposes. The questionnaires took approximately $10 \mathrm{mins}$ to complete, and at the end, participants were required to indicate whether they were willing to be interviewed. If yes, they were then invited to leave their contact details, and from this group, we selected 12 participants to interview. The criteria for selecting interviewees were that the 6 selected interviewees demonstrated different levels of feedback orientation (high, moderate, and low), and another 6 showed different frequencies of SRL strategy use (high, moderate, and low) based on their questionnaire responses. The 12 interviewees were undergraduates who came from the selected five universities and all had received electronic WCF online. The semi-structured, 40-min online interviews were conducted in Chinese, the participants' first language, and digitally audio-recorded with the interviewee's permission. The interviews were subsequently transcribed verbatim into Chinese for further analysis.

\section{Data Analysis}

Exploratory factor analysis (EFA) was performed on the FOQ and WSSRLQ data to examine the internal structure of these questionnaires and to verify whether they both produced the expected results. Specifically, a principal component analysis was performed to scale the data down into smaller units of manageable dimensions rather than unveil the deeper underlying constructs. Prior to performing the EFA, univariate normality was checked by looking at the skewness and kurtosis of the quantitative data at item level, and the Kaiser-Meyer-Olkin of sampling adequacy and Bartlett's test of sphericity were checked to determine the data's suitability for EFA. Afterwards, reliabilities of FUQ and WSSRLQ were estimated in the form of Cronbach alpha at both item and factor levels. Then, descriptive analysis at item levels was conducted for both the FOQ and WSSRLQ. Finally, a multiple linear regression was run to explore the relationship between students' feedback orientation towards WCF and SRL writing strategies.

Interviews allow for an in-depth and thorough understanding of personal feelings and experiences (Patton, 2015). The qualitative data, therefore, were analysed inductively and recursively according to the following process. First, the interview transcripts were read and reread to pinpoint recurring words, phrases, and clauses in relation to feedback orientation, SRL strategies and their relations. Then, open coding was performed to yield a cluster of codes for feedback orientation and SRL strategies and the initially identified codes were then translated into significant categories. Axial coding (Strauss \& Corbin, 1998) was then conducted to compare and integrate the categories and the logical connections between these categories were identified to obtain the overall profiles of students' feedback orientation and SRL writing strategies, thus producing different themes. For example, the theme of how interviewees responded to WCF was elicited through figuring out the two categories: individual behaviours (what they did on their own) and social behaviours (what they did with significant others). Within-case analysis performed on each participant yielded themes and then cross-case analysis was conducted to compare and integrate participants in terms of these emerging themes. The author re-analysed the interview data to ensure the trustworthiness of the qualitative findings.

\section{Results}

\section{Feedback Orientation Towards WCF}

\section{Quantitative Results of Feedback Orientation Towards Online WCF}

A principal component analysis with oblimin rotation was run on the 13 items of FOQ. Univariate normality was examined, and the results showed that the skewness and kurtosis of the 13 items were within the range of -3.30 to $+3.30(p<0.01)$. The Kaiser-Meyer-Olkin of sampling adequacy was 0.85 , which was above the cut-off threshold of 0.5, thus indicating that EFA was able to generate discrete and reliable factors. Bartlett's test of sphericity $\left(\chi^{2}=1760.13, \mathrm{~d} f=78, p<0.01\right)$ suggested that the associations between items were large enough to perform the EFA. Results of the EFA on the 13 items showed that the two factors' eigenvalue was above one, and that this in total explained $54.75 \%$ of the variance. Consistent with the two dimensions found by Waller and Papi (2017), feedback-seeking orientation (Factor 1, items 1-7, Cronbach's $\alpha=0.84$ ) and feedback-avoiding orientation (Factor 2 , items $8-13$, Cronbach's $\alpha=0.79$ ) were both found in our study. Table 1 summarises the mean, standard deviation, factor loadings, eigenvalues and Cronbach $\alpha$ of each factor.

Results of descriptive analysis further showed that the surveyed students had positive attitudes towards WCF, as the mean of the items related to feedback-seeking orientation ranged from 4.27 to 5.43. In contrast, students had a lower mean on the items representing feedback-avoiding orientation, which ranged from 1.82 to 2.53 . 
Table 1 EFA results of FOQ with factor loading and descriptive statistics

\begin{tabular}{|c|c|c|c|c|}
\hline \multirow[t]{2}{*}{ Item } & \multirow[t]{2}{*}{ Mean } & \multirow[t]{2}{*}{$S D$} & \multicolumn{2}{|c|}{ Factor } \\
\hline & & & 1 & 2 \\
\hline 1. When I do not understand my teacher's comments on my English writing, I talk to him/her online & 4.27 & 1.07 & .51 & \\
\hline $\begin{array}{l}\text { 2. I like when my teacher corrects all of my English writing mistakes (grammar, content, organisation, spelling, } \\
\text { punctuation) }\end{array}$ & 4.89 & 1.03 & .69 & \\
\hline 3. I like when my teacher uses correction symbols to show me my English writing mistakes & 4.92 & .92 & .76 & \\
\hline 4. When I get my English writing papers back, I read all of the comments carefully & 5.43 & .75 & .70 & \\
\hline 5. English written corrective feedback from my teacher helps me to be a better writer & 5.25 & .76 & .84 & \\
\hline 6. I remember the English writing mistakes my teacher points out to me and I try not to make them again & 5.06 & .81 & .80 & \\
\hline $\begin{array}{l}\text { 7. I like when my teacher writes questions on my English writing paper to make me think about my writing (not just } \\
\text { gives me the answer) }\end{array}$ & 5.37 & .75 & .77 & \\
\hline 8. I like when my teacher only writes a grade and not comments on my English writing paper & 2.53 & 1.28 & & .50 \\
\hline 9. When I do not understand my teacher's comments on my English writing paper, I ignore them & 2.42 & 1.10 & & 62 \\
\hline 10. After peer review, I never look at my classmate's comments on my English writing paper & 2.11 & .98 & & .82 \\
\hline 11. When I get my English writing papers back, I only look at the grade & 2.03 & .95 & & .83 \\
\hline 12. I would like to be told only what I did right in my English writing paper & 2.27 & 1.33 & & .69 \\
\hline 13. I don't care about receiving feedback on my English writing papers & 1.82 & .91 & & .72 \\
\hline Eigenvalue & & & 37.45 & 17.30 \\
\hline Cronbach's $\alpha$ & & & .84 & \\
\hline
\end{tabular}

\section{Qualitative Results of Feedback Orientation Towards Online WCF}

Three themes were generated by analysing students' interview data. The first theme was students' general perceptions of online WCF. Students reported in interviews that 'teachers' feedback guided me to know what a highquality composition was like and directed me to work hard on the right track" (S6) and "teachers could help me find out my writing problems and improve my writing that I had otherwise failed to do" (S5). Students on most occasions had positive attitudes towards teachers' online written feedback. However, students only benefited from the individual online feedback in that "only the one-on-one feedback was specifically targeted to me compared to the overall feedback which was concluded based on all the students' writing mistakes" (S12). On the contrary, online feedback had at least one admitted drawback. As S2 said, "the online teaching and feedback sometimes discouraged me from engaging more in writing class." The second theme was the uniqueness of online WCF. As perceived by interviewees, what was unique about the online feedback, for example, was that "teachers' online feedback is clear and can be reviewed indefinitely" (S4) and "there was no face-to-face feedback on my writing, which was relaxing for me" (S3). Moreover, "the effectiveness of feedback was even enhanced during COVID-19 as teachers offered more tutorials and feedback" (S1). For instance, students reported that they "usually asked more questions online within a social media or online teaching forum which was critical for improvement in English writing" (e.g. S6). The third theme was the responses after receiving teachers' WCF online. Upon receiving teachers' feedback, they liked to "read teachers' feedback carefully and correct the composition accordingly" (e.g. S10) or "consulted classmates if there were confusions and then continued to make revisions" (S9). What students benefited most from teachers' online feedback was "the logical problems teacher pointed out in the composition" (S11). Generally, students perceived the online English writing feedback to be positive, and they mostly showed feedback-seeking orientation towards WCF.

\section{The Use of SRL Strategies in L2 Writing}

\section{Quantitative Results of the Use of SRL Strategies in L2 Writing}

Next, as with the FOQ, the skewness and kurtosis of these 40 SRL items were also within the range of -3.30 to + $3.30(p<0.01)$. This questionnaire's Kaiser-MeyerOlkin of sampling adequacy was 0.94 , which meant that the EFA was able to yield reliable and discrete factors, and Bartlett's test of sphericity $\left(\chi^{2}=10,504.25, \mathrm{~d} f=780\right.$, $p<0.01)$ indicated that the correlations between items were large enough to perform an EFA. The results of the EFA on the WSSRLQ showed that the generated factors' eigenvalues were all above one and in total explained $76.33 \%$ of the variance. Our study identified eight factors which generally echoed the original WSSRLQ developed 
by Teng and Zhang (2016), who isolated nine discrete factors. However, items 22-25, which constituted a factor in the original WSSRLQ, were double-loaded in our study, so they were removed. The Cronbach's $\alpha$ of the whole questionnaire was 0.96 . Factor 1 and Factor 2 belonged to cognitive strategies, while Factor 3 and Factor 4 were classified as metacognitive strategies. Factor 5 indicated social behaviour strategies, while Factors 6,7 and 8 belonged to motivational regulation strategies. Table 2 summarises the factor loadings, eigenvalues, and Cronbach's $\alpha$ of each factor in our WSSRLQ results analysis. The results of descriptive analysis on the WSSRLQ are presented in Table 3. It should be noted that the lower mean found for social behaviour strategies (3.85 on a 6-point scale) suggested that students might not use this type of strategies very often while completing writing tasks during COVID-19. Particularly, students may not work

Table 2 EFA results of WSSRLQ with factor loadings

\begin{tabular}{|c|c|c|c|c|c|c|c|c|}
\hline \multirow[t]{2}{*}{ Item } & \multicolumn{8}{|c|}{ Factor } \\
\hline & 1 & 2 & 3 & 4 & 5 & 6 & 7 & 8 \\
\hline 1 & .43 & & & & & & & \\
\hline 2 & .89 & & & & & & & \\
\hline 3 & .87 & & & & & & & \\
\hline 4 & .86 & & & & & & & \\
\hline 5 & .82 & & & & & & & \\
\hline 6 & .75 & & & & & & & \\
\hline 7 & & .30 & & & & & & \\
\hline 8 & & .40 & & & & & & \\
\hline 9 & & .39 & & & & & & \\
\hline 10 & & & .62 & & & & & \\
\hline 11 & & & .67 & & & & & \\
\hline 12 & & & .57 & & & & & \\
\hline 13 & & & & .86 & & & & \\
\hline 14 & & & & .92 & & & & \\
\hline 15 & & & & .75 & & & & \\
\hline 16 & & & & .62 & & & & \\
\hline 17 & & & & .69 & & & & \\
\hline 18 & & & & .70 & & & & \\
\hline 19 & & & & & .81 & & & \\
\hline 20 & & & & & .78 & & & \\
\hline 21 & & & & & .83 & & & \\
\hline 26 & & & & & & .82 & & \\
\hline 27 & & & & & & .82 & & \\
\hline 28 & & & & & & .89 & & \\
\hline 29 & & & & & & .81 & & \\
\hline 30 & & & & & & & .60 & \\
\hline 31 & & & & & & & .86 & \\
\hline 32 & & & & & & & .82 & \\
\hline 33 & & & & & & & .70 & \\
\hline 38 & & & & & & & & .49 \\
\hline 39 & & & & & & & & .55 \\
\hline 40 & & & & & & & & .61 \\
\hline Eigenvalue & 6.56 & 2.08 & 2.57 & 44.05 & 3.81 & 3.27 & 2.86 & 6.62 \\
\hline Cronbach's $\alpha$ & .92 & .83 & .83 & .93 & .88 & .91 & .84 & .84 \\
\hline
\end{tabular}

Items 22-25 and 34-37 were double-loaded, so they were deleted

Factor 1 text processing, Factor 2 course memory, Factor 3 idea planning, Factor 4 goal-oriented monitoring and evaluating (GME), Factor 5 peer learning, Factor 6 interest enhancement, Factor 7 motivational self-talk, Factor 8 emotional control 
Table 3 Descriptive statistics of WSSRLQ

\begin{tabular}{|c|c|c|}
\hline Item & Mean & $S D$ \\
\hline 1. When writing, I use some literary devices to make the composition more interesting & 4.46 & .99 \\
\hline 2. When writing, I check grammar mistakes & 4.77 & .99 \\
\hline 3. When writing, I check spelling and punctuation & 4.81 & .97 \\
\hline 4. When writing, I check the structure for logical coherence & 4.76 & .95 \\
\hline 5. When writing, I check the cohesiveness or connection among sentences & 4.80 & .93 \\
\hline 6. When writing, I check whether the topic and the content have been clearly expressed & 4.87 & .87 \\
\hline 7. I write useful words and expressions taught in writing courses to help me remember them & 4.76 & .94 \\
\hline 8. I speak out useful words and expressions taught in writing courses to help me remember them & 4.55 & .96 \\
\hline 9. I read my class notes and the course material over and over again to help me remember them & 4.02 & 1.0 \\
\hline 10. Before writing, I read related articles to help me plan & 4.27 & 1.14 \\
\hline 11. Before writing, I use the internet to search for related information to help me plan & 4.63 & .99 \\
\hline 12. Before writing, I think about the core elements of a good composition I have learned to help me plan & 4.46 & 1.02 \\
\hline 13. When learning to write, I set up goals for myself in order to direct my learning activities & 4.24 & 1.00 \\
\hline 14. When learning to write, I check my progress to make sure I achieve my goal & 4.31 & .99 \\
\hline 15. I evaluate my mastery of the knowledge and skills learned in writing courses & 4.37 & .92 \\
\hline 16. I monitor my learning process in writing courses & 4.21 & 1.04 \\
\hline 17. When writing, I tell myself to follow my plan & 4.37 & .99 \\
\hline 18. When learning to write, I set up a learning goal to improve my writing & 4.16 & 1.07 \\
\hline 19. I brainstorm with my peers to help me write & 3.94 & 1.28 \\
\hline 20. I discuss with my peers to have more ideas to write with & 4.10 & 1.27 \\
\hline 21. I work with my peers to complete a writing task & 3.51 & 1.31 \\
\hline 26. I look for ways to bring more fun to the learning of writing & 4.42 & 1.05 \\
\hline 27. I choose interesting topics to practice writing & 4.51 & 1.11 \\
\hline 28. I connect the writing task with my real life to intrigue me & 4.70 & .98 \\
\hline 29. I try to connect the writing task with my personal interest & 4.72 & .98 \\
\hline 30. I remind myself about how important it is to get good grades in writing courses & 4.61 & .94 \\
\hline 31. I tell myself that it is important to practice writing to outperform my peers & 4.07 & 1.20 \\
\hline 32. I compete with other students and challenge myself to do better than them in writing courses & 4.19 & 1.08 \\
\hline 33. I tell myself to practice writing to get good grades & 4.41 & 1.02 \\
\hline 38. I tell myself not to worry when taking a writing test or answering questions in writing courses & 4.50 & 1.02 \\
\hline 39. I tell myself to keep on writing when I want to give it up & 4.56 & .90 \\
\hline 40. I find ways to regulate my mood when I want to give up & 4.77 & .84 \\
\hline Cognitive strategies & 4.64 & .75 \\
\hline Metacognitive strategies & 4.34 & .81 \\
\hline Social behaviours strategies & 3.85 & 1.15 \\
\hline Motivational regulation strategies & 4.50 & .72 \\
\hline
\end{tabular}

with peers to complete a writing task very frequently (mean 3.51 ) as shown in Item 21 .

\section{Qualitative Results of the Use of SRL Strategies in L2 Writing}

Cognitive and Metacognitive Strategies were Used During Online Writing The qualitative results showed that students used a variety of strategies when writing in English online. In terms of cognitive strategies, students believed it was convenient to search for online materials to support writing. For instance, S5 articulated, "I can check the English words and native-like expressions via an online dictionary to make the use of my vocabulary words fancier." Translation also still played a role in students' online writing. As S2 illustrated, "I would like to write in my mind in Chinese and then translate them into English." With regard to metacognitive strategies, students commonly reported that they preferred to "plan how to write beforehand" (e.g. S3), as well as "monitor what they have 
Table 4 A multiple regression from feedback orientation to self-regulated learning writing strategies

\begin{tabular}{lcccc}
\hline & Cognitive strategies & Metacognitive strategies & Social behaviour strategies & Motivational regulation strategies \\
\hline Feedback-seeking orientation & $.61^{* *}$ & $.55^{* *}$ & $.31^{* *}$ & $.59^{* *}$ \\
Feedback-avoiding orientation & -.06 & -.03 & -.02 & -.03 \\
\hline
\end{tabular}

$P$ values less than 0.01 are summarised with two asterisks and less than 0.05 are summarised with one asterisk

${ }^{*} p<.05$

$* * p<.01$

written and check the whole manuscript after writing in terms of vocabulary, sentence structure, and logical connections between sentences" (e.g. S9). Students also expressed that it was easy to make continuous revisions while writing online. For example, S9 mentioned that "I did not need to write an outline prior to writing because I could keep revising during online writing."

Social Behaviour Strategies Were Seldomly Used During Online Writing There were still peer interactions during online writing classes, but these only occurred when teachers asked students to work with their classmates to complete a composition collaboratively or to seek feedback from one another, not during the individual writing process. S5 told us, "we three students exchanged ideas on social media, offered our own opinions and then each person was responsible for a part of this composition." Despite some evidence of continued peer interaction during the writing process, peer suggestions and feedback were limited in three main ways. First, as S6 said, "peers' writing proficiency may affect the quality of feedback they provided, and peers were unable to identify all the mistakes" (S6). Second, S10 reported that "my classmates tended to only give positive comments online" (S10). Third, some students expressed concern that "it was inconvenient and less effective to chat online with my peers" (S1). Finally, although most students said they were motivated to improve their English writing, they did not elaborate and provide further qualitative commentary on their use of motivational regulation strategies.

\section{The Association Between Feedback Orientation and SRL Strategies}

Table 4 displays the correlations found between students' feedback orientation towards online WCF and the use of SRL strategies during the COVID-19 pandemic. The results of the multiple regression analysis showed that feedback-seeking orientation was associated positively and significantly with cognitive, metacognitive, social behaviour and motivational regulation strategies. However, feedback-avoiding orientation was not related to these four types of strategies.
The qualitative findings with two themes further contributed to a deeper understanding of these results. The first theme was that both teachers' praise and negative comments could enable them to work hard on their writing. For example, S8 mentioned that "when my teacher showed the merits of my writing to all students, I felt delighted to continue to achieve more progress." Students' writing problems as pointed out by teachers can also motivate students to practice more. S7 explained that "although I felt a bit disappointed upon seeing my teachers' negative comments, I could recover quickly and was motivated because I realised that I still had space for improvement," Second, in addition to the online feedback, students were motivated through interacting with teachers online, especially when their own beliefs were recognised. "When I disagreed with my teachers' feedback, I would like to communicate with her/him online; when my thoughts were finally accepted by my teachers, I was motivated to subsequently write more." Overall, these qualitative findings generally corroborated the quantitative findings in the present study.

\section{Discussion}

This study examined what university students' feedback orientation towards WCF and their use of SRL strategies were like, exploring the association between their feedback orientation and SRL strategies. In response to Q1, quantitative results demonstrated that students generally held positive attitudes towards online WCF. The qualitative findings further indicated that teaching online during COVID-19 led teachers to expand online tutorials and feedback, that multiple students can benefit from a teachers' feedback to one particular student, and this online feedback created a comfortable space in which students could review the online feedback many times. The qualitative findings supported the finding by Fageeh and Mekheimer (2013) and Bailey and Lee (2020) that online synchronous teaching had its merits in facilitating students' language learning. Both quantitative and qualitative findings revealed that the online teaching and feedback can improve students' English writing, which corroborated 
with previous findings (e.g. Grigoryan, 2017). Responding to Q2, the quantitative questionnaire results showed that students used fewer social behaviour strategies than cognitive, metacognitive, and motivational regulation strategies. The qualitative results, such as the interviewee's evidence of less frequent peer collaborations, further supported this quantitative finding. Interviewees reported that the effectiveness of online peer collaboration was restricted by peers' writing proficiency and tendency to give compliments, as well as the inconveniences associated with communicating online. The limitation of peer feedback existed online, but the peer feedback might work differently in face-to-face live communications in classrooms. Consistent with quantitative findings, the qualitative results showcased that students tended to use cognitive and metacognitive strategies during online writing, which was supported by Teng and Zhang's (2016) findings. An interesting finding was that the online writing may let students use fewer metacognitive strategies, such as initial planning before writing. Responding to Q3, students' feedback-seeking orientation significantly predicted SRL writing strategies, which was consistent with the findings of Ekholm et al. (2015). The quantitative findings were further supplemented by the qualitative findings that teachers' feedback, either positive or negative, can motivate students to work hard on their writing, and that the interactions between teachers and students based on teachers' feedback can also motivate students to engage more deeply in their writing practices. Besides, based on the qualitative findings of the present study, it was gauged that students' feedback orientation was an individual characteristic (Waller \& Papi, 2017) regardless of teachers' praise and critique. Both quantitative and qualitative findings were in line with the findings of Kheiri et al. (2019) that have proved the positive effect of online WCF on the use of SRL writing strategies. However, the interview data did not explicitly elicit participants' use of motivational regulation strategies, which was called for future research, such as narrative inquiry, to verify this issue.

Our study demonstrated the individual differences in students' feedback orientation, which provides a new potential explanation for the findings in existing studies as to why students react to WCF differently (e.g. Ferris, 2010). We also identified a pattern among Chinese learners of English in which they vary their use of SRL strategies (Sun \& Wang, 2020). The nature of online teaching and feedback, to some extent, shaped these findings. Although we would expect it to take time for students to adjust themselves to online teaching and feedback, they had positive attitudes towards online WCF early on in this COVID-19 period. One reason was that the online WCF has merits, as discussed above. Another is that students' feedback-seeking behaviours appear to not be influenced by the delivery of online feedback based on the quantitative and qualitative findings. This suggests that students who have a feedback-seeking orientation can apply the relevant use of SRL strategies regardless of the mode of instruction delivery (Kheiri et al., 2019; Papi et al., 2019). The qualitative findings revealed that students were actively engaged with online WCF. It can be inferred that WCF is not only a teaching resource for teachers but also a learning resource for students (Papi et al., 2019), which can also explain why students in our study still show feedbackseeking orientation during COVID-19.

Although English writing courses were taught online, students' use of SRL strategies was moderately high, all types being rated an average above 4 except for social behaviour strategies. Online teaching is different from face-to-face classroom teaching, where students can meet and talk in person, which may partially explain why students used few social behaviour strategies during COVID19. Hence, students' online language learning seems more dynamic during COVID-19 than in classrooms (Bailey \& Lee, 2020). Therefore, a teaching approach that is dynamic according to the teaching environment, such as requiring fewer peer interactions, is advocated; otherwise, teachers' time and effort will be wasted (Enginarlar, 1993). Although students' interview accounts indicate that online teaching and feedback may sometimes affect their engagement and motivation level, the descriptive results on motivational regulation strategies (Mean 4.50 out of 6) reflect that students' motivation level during online learning was probably not greatly influenced. It means that online teaching can still to some extent enhance students' L2 writing (Grigoryan, 2017). Our study indicated that students employed a range of SRL writing strategies, despite the less use of social behaviour strategies, which was slightly different from Sun and Wang's (2020) findings that Chinese university students had infrequent use of SRL writing strategies. The possible reason is that under the influence of COVID-19, the online learning has enabled students to use more SRL writing strategies. Thus, since online teaching and feedback also has irreplaceable advantages, the findings of our study open a window for exploring the possibilities for and feasibilities of combining online and offline teaching in future writing courses.

The present study additionally has pedagogical implications. First, since online WCF is generally accepted positively by students with feedback-seeking-directed attitudes, it can be continued as a supplemental tool for inperson English writing classes in the post-COVID-19 era. Second, teachers should provide some guidance on how to apply SRL writing strategies during the writing process in a direct way or with examples and scaffolding. To achieve this goal, teachers should know what kinds of strategies are used frequently and infrequently by students for better 
instructional interventions in the online medium. Third, when considering peer feedback or interactions, teachers need to be mindful of each individual's writing proficiency, students' tendency to give only compliments to peers, and their willingness to collaborate with peers. This is particularly the case with online teaching during COVID-19, when it is inconvenient for peers to interact online. Finally, despite the helpful pedagogical implications found, this study's limitations should also be considered. We did not take the variable of writing outcomes into account, and further studies could address this issue by analysing students' final written products, thus stepping further into exploring the relationship between feedback orientation, SRL strategies, and writing outcomes.

Acknowledgements I would like to express my heartfelt thanks to the editor and two TAPER reviewers for their insightful comments and feedback on the previous drafts of this manuscript.

Funding This work is funded by University Philosophy and Social Sciences Collaborative Innovation Team in Chongqing "Language Big Data Research and Application Innovation Team”.

\section{Appendix}

1. What did you think of teachers' online English writing teaching activities during the COVID-19?

2. How did your English writing class work during the online teaching period of the epidemic? How do you feel about this?

3. Do you think the online teaching and learning of English writing during the epidemic is different from that during the non-epidemic?

4. In online teaching during the epidemic, how did your English teacher give you written feedback on your composition? How do you feel?

5. After receiving and reading the teacher's feedback on your writing, how did you react to and how do you think about the feedback? Why?

6. How would you deal with the feedback from your teacher on your English composition?

7. What kind of impact did the teacher's feedback on your English composition have on your English writing study? In what ways?

8. In online teaching during the epidemic, how did you learn or practice English writing in and out of class?

9. Can you describe your writing experiences on your computer (online)?

10. When you wrote online, what did you usually pay attention to?

11. When you wrote online, what writing strategies do you generally use to help you write better? Can you give specific examples?
12. When you wrote online, how did you ensure the quality of your composition?

13. What factors do you think affected your online English writing? Please be specific.

14. Have you ever worked with classmates to complete a writing task? Can you describe it?

15. How do you feel like online English writing? Why?

16. Do you think teacher's feedback has a great influence or improvement on your online English writing? Why?

17. How do you view your English writing abilities? Do you think your English writing abilities can be improved?

18. Regarding the above questions, do you have anything else to add?

\section{References}

Bai, B., \& Guo, W. (2018). Influences of self-regulated learning strategy use on self-efficacy in primary school students' English writing in Hong Kong. Reading \& Writing Quarterly, 34(6), 523-536. https://doi.org/10.1080/10573569.2018.1499058

Bailey, D. R., \& Lee, A. R. (2020). Learning from experience in the midst of COVID-19: Benefits, challenges, and strategies in online teaching. CALL-EJ, 21(2), 178-198

Bandura, A. (2011). A social cognitive perspective on positive psychology. Revista de Psicología Social, 26(1), 7-20. https://doi.org/10.1174/021347411794078444

Bao, W. (2020). COVID-19 and online teaching in higher education: A case study of Peking University. Human Behavior and Emerging Technologies, 2(2), 113-115. https://doi.org/10.1002/hbe2.191

Chen, S., Nassaji, H., \& Liu, Q. (2016). EFL learners' perceptions and preferences of written corrective feedback: A case study of university students from Mainland China. Asian-Pacific Journal of Second and Foreign Language Education, 1(1), 1-17. https://doi.org/10.1186/s40862-016-0010-y

Creswell, W. J. (2013). Research design: Qualitative, quantitative and mixed method approaches. Thousand Oaks: Sage Publication.

De Silva, R., \& Graham, S. (2015). The effects of strategy instruction on writing strategy use for students of different proficiency levels. System, 53, 47-59. https://doi.org/10.1016/j.system.2015.06.009

Ekholm, E., Zumbrunn, S., \& Conklin, S. (2015). The relation of college student self-efficacy toward writing and writing selfregulation aptitude: Writing feedback perceptions as a mediating variable. Teaching in Higher Education, 20(2), 197-207. https://doi.org/10.1080/13562517.2014.974026

Enginarlar, H. (1993). Student response to teacher feedback in EFL writing. System, 21(2), 193-204. https://doi.org/10.1016/0346-251X(93)90041-E

Evans, C. (2013). Making sense of assessment feedback in higher education. Review. of Educational Research, 83, 70-120. https://doi.org/10.3102/0034654312474350

Fageeh, A., \& Mekheimer, M. A. A. (2013). Effects of Blackboard on EFL Academic Writing and Attitudes. JALT CALL Journal, 9(2), 169-196. https://doi.org/10.29140/jaltcall.v9n2.154

Ferris, D. R. (2010). Second language writing research and written corrective feedback in SLA: Intersections and practical 
applications. Studies in Second Language Acquisition, 32(2), 181-201. https://doi.org/10.1017/S0272263109990490

Flower, L., \& Hayes, J. R. (1981). A cognitive process theory of writing. College Composition and Communication, 32(4), 365-387

Glaser, C., \& Brunstein, J. C. (2007). Improving fourth-grade students' composition skills: Effects of strategy instruction and self-regulation procedures. Journal of Educational Psychology, 99(2), 297-310. https://doi.org/10.1037/0022-0663.99.2.297

Grigoryan, A. (2017). Feedback 2.0 in online writing instruction: Combining audio-visual and text-based commentary to enhance student revision and writing competency. Journal of Computing in Higher Education, 29(3), 451-476. https://doi.org/10.1007/s12528017-9152-2

Han, Y. (2019). Written corrective feedback from an ecological perspective: The interaction between the context and individual learners. System, 80, 288-303. https://doi.org/10.1016/j.system.2018.12.009

Havnes, A., Smith, K., Dysthe, O., \& Ludvigsen, K. (2012). Formative assessment and feedback: Making learning visible. Studies in Educational Evaluation, 38(1), 21-27. https://doi. org/10.1016/j.stueduc.2012.04.001

Kheiri, S., Soleimani, H., Jafarigohar, M., \& RostamiAbooSaeedi, A. A. (2019). The effect of web-integrated instruction and feedback on self-regulated learning ability of Iranian EFL learners. Iranian Journal of English for Academic Purposes, 8(1), 35-48

Mackey, A., \& Oliver, R. (2002). Interactional feedback and children's L2 development. System, 30(4), 459-477. https://doi.org/10.1016/S0346-251X(02)00049-0

Nassaji, H. (2016). Anniversary article Interactional feedback in second language teaching and learning: A synthesis and analysis of current research. Language Teaching Research, 20(4), 535-562. https://doi.org/10.1177/1362168816644940

Nguyen, P. M., Terlouw, C., \& Pilot, A. (2006). Culturally appropriate pedagogy: The case of group learning in a Confucian Heritage Culture context. Intercultural Education, 17(1), 1-19. https://doi.org/10.1080/14675980500502172

Palermo, C., \& Thomson, M. M. (2018). Teacher implementation of selfregulated strategy development with an automated writing evaluation system: Effects on the argumentative writing performance of middle school students. Contemporary Educational Psychology, 54, 255-270. https://doi.org/10.1016/j.cedpsych.2018.07.002

Papi, M., Rios, A., Pelt, H., \& Ozdemir, E. (2019). Feedback-seeking behavior in language learning: Basic components and motivational antecedents. The Modern Language Journal, 103(1), 205-226. https://doi.org/10.1111/modl.12538

Patton, M. Q. (2002). Two decades of developments in qualitative inquiry: A personal, experiential perspective. Qualitative Social
Work,

$1(3)$,

$261-283$

https://doi.org/10.1177/1473325002001003636

Patton, M. Q. (2015). Qualitative research \& evaluation methods. (4th ed.). Sage.

Sheen, Y. (2007). The effect of focused written corrective feedback and language aptitude on ESL learners' acquisition of articles. TESOL Quarterly, 41(2), 255-283. https://doi.org/10.1002/j.1545-7249. 2007.tb00059.x

Storch, N., \& Wigglesworth, G. (2010). Learners processing, uptake, and retention of corrective feedback on writing: Case studies. Studies in Second Language Acquisition, 32(2), 303-334. https://doi.org/10.1017/S0272263109990532

Strauss, A., \& Corbin, J. (1998). Basics of qualitative research techniques. Sage publications. https://doi.org/10.1016/j.tate.2017.01.010

Sun, T., \& Wang, C. (2020). College students' writing self-efficacy and writing self-regulated learning strategies in learning English as a foreign language. System, 90, 102221. https://doi.org/ 10.1016/j.system.2020.102221

Teng, L. S., \& Zhang, L. J. (2016). A questionnaire-based validation of multidimensional models of self-regulated learning strategies. The Modern Language Journal, 100(3), 674-701. https://doi. org/10.1111/modl.12339

Truscott, J. (1996). The case against grammar correction in L2 writing classes. Language Learning, 46, 327-369. https://doi.org/10.1111/ j.1467-1770.1996.tb01238.x

Waller, L., \& Papi, M. (2017). Motivation and feedback: How implicit theories of intelligence predict L2 writers' motivation and feedback orientation. Journal of Second Language Writing, 35, 54-65. https://doi.org/10.1016/j.jslw.2017.01.004

Wang, C., Schwab, G., Fenn, P., \& Chang, M. (2013). Self-efficacy and self-regulated learning strategies for English language learners: Comparison between Chinese and German college students. Journal of Educational and Developmental Psychology, 3(1), 173-191. https://doi.org/10.5539/jedp.v3n1p173

Zimmerman, B. J. (2000). Attaining self-regulation: A social cognitive perspective. In M. Boekaerts, P. R. Pintrich, \& M. Zeidner (Eds.), Handbook of self-regulation. (pp. 13-40). Academic Press.

Zumbrunn, S., Marrs, S., \& Mewborn, C. (2016). Toward a better understanding of student perceptions of writing feedback: A mixed methods study. Reading and Writing, 29(2), 349-370. https://doi.org/10.1007/s11145-015-9599-3

Publisher's Note Springer Nature remains neutral with regard to jurisdictional claims in published maps and institutional affiliations. 